\title{
EFEITOS DA ABLAÇÃO E DA EXCITAÇĀO DO HIPOCAMPO NO HOMEM
}

\author{
JAYME VIANNA*
}

A presente série de observações foi inspirada no trabalho de revisão de Brodal ${ }^{2}$ sôbre o hipocampo e nas experiências levadas a efeito no macaco por Ward, McCulloch e Smith sôbre o cíngulo anterior, área para onde se projeta indiretamente o hipocampo por intermédio do corpo mamilar e do grupo nuclear antericr do tálamo.

Os trabalhos experimentais mostraram que o cíngulo anterior, além de exercer poderosa atividade supressora sôbre outras partes do córtex cerebral, está também relacionado com a conduta e a emotividade. As experiências de excitação do cíngulo anterior empreendidas por Smith ${ }^{4}$, produziram, entre outros fenômenos, parada da respiração e relaxamento muscular acentuado. A elevação do limiar de excitabilidade do córtex précentral foi observada por McCulloch ${ }^{3}$.

Mais interessantes são os resultados da ablação, com o que se observam modificações da conduta, verificadas pela primeira vez por Ward ${ }^{5}$; os animais tornam-se mais dóceis e não mais apresentam atitudes e reações que exprimem mêdo e ansiedade.

Levando em consideração o fato de que o cíngulo anterior recebe impulsos aferentes indiretos, em grande parte através do hipocampo, não é impossível que a atividade do primeiro seja influenciada pela ablação ou excitação do segundo, podendo, conseqüentemente, ocasionar modificações da conduta. Por outra parte, pelo mesmo motivo, seria possível modifi. car o limiar de excitabilidade cortical, estimulando ou extirpando o hipocampo; o sentido desta modificação seria impossível de prever sem uma verificação experimental ou clínica, porém, é fácil de se conceber, a priori, que possa ter alguma influência na evolução de algumas enfermidades nervosas e mentais, como sejam a epilepsia sem foco determinado e certos distúrbios caracterizados por alterações da conduta. Os efeitos da ablação do hipocampo nesses casos não devem ser superponíveis aos verificados por Le Beau ${ }^{2}$ após a ablação do cíngulo anterior; neste último caso há

Trabalho entregue para publicação em 30 abril 1953.

* Do Serviço de Neurocirurgia do Hospital Juliano Moreira (Salvidor, (Bahia). 
supressão funcional total do cíngulo anterior, ao passo que, na ablação do hipocampo, há modificação da atividade daquela área pela supressão de parte dos impulsos que lhe são aferentes.

Foi nesta série de hipóteses que fundamentamos a iniciativa de intervir sôbre o hipocampo.

\section{MATERIAL, TÉCNICA E RESULTADOS}

No total, até o momento, operamos 10 pacientes: 5 ablações bilaterais, duas ablações unilaterais e três acessos ao hipocampo, sem ablação. Nestes três últimos casos, a intervenção foi feita a título de contraprova porque na técnica que usamos o acesso ao hipocampo é feito através da terceira circunvolução temporal, por via transventricular; nestas condições, são sacrificadas muitas fibras aferentes e eferentes do lobo fusiforme, surgindo, assim, a dúvida quanto a saber se os efeitos são em verdade conseqüentes à ablação do hipocampo ou ao "undercutting" do lobo fusiforme.

Éstes três casos serviram também para que se observassem os efeitos do estímulo do hipocampo, porque a dificuldade que deparamos inicialmente em verificar êstes efeitos consistia na impossibilidade de encontrarmos pacientes que pudessem ser submetidos à intervenção sob anestesia local e que colaborassem satisfatòriamente. Assim, nestes casos, aproveitamos a oportunidade para, em um dêles, implantarmos no hipocampo um eletrodo cuja extremidade oposta foi fixada ao couro cabeludo, sendo êste em seguida suturado. Cessado o efeito da anestesia, fizemos a excitação por meio de corrente pulsátil com freqüência de 5 e 10 ciclos por segundo. Nos outros dois casos implantamos uma agulha de fino calibre, cujo pavilhão foi fixado ao couro cabeludo; ulteriormente, após a cessação do efeito da anestesia, injetamos, em um, acetilcolina e prostigmina e, em outro, estricnina.

Efeitos do estímulo elétrico - $\mathrm{O}_{\mathrm{s}}$ efeitos conseguidos com excitação monopolar com 5 e 10 ciclos por segundo, consistirari no aumento da amplitude e da freqüência respiratória (em poucos segundos a freqüêrıcia aumentou de 22 para 36 por minuto) e aumento da freqüência do pulso (mais de 10\%). Não foi observado efeito algum sôbre a pressão arterial. 0 paciente não acusou distúrbio subjetivo algum.

Estímulo químico - A) Injeção de acetilcolina e prostigmina: não verificamos efeito apreciável sôbre a freqüência do pulso nem sôbre o ritmo respiratório; as únicas alterações que observamos consistiram na elevação da pressão arterial mínima (elevação de 8 para 9,5) e no aparecimento de extrassístoles, que logo cederam espontâneamente. B) Injeção de estricnina: não foi observado efeito apreciável sôbre a pressão arterial e a freqüência do pulso; notamos, como no estímulo elétrico, aumento 
da amplitude respiratória e, além disso, sinais de inquieturde por parte do paciente, como se alguma coisa o incomodasse; entretanto, não houve sensação subjetiva alguma.

No que se refere aos resultados gerais, nenhuma conclusão definitiva podemos ainda tirar por ser pequeno o número de casos observados e por ser insuficiente o tempo de observação. Entretanto, parece não haver influência sensível sôbre a freqüência e a forma das crises convulsivas nos pacientes epiléticos. Em dois meninos epiléticos, com distúrbios graves de conduta, houve modificaçáo acentuada: um dêles pôde voltar a conviver com a família, tornando-se dócil e obediente; o outro, turbulento e homossexual ativo, tornou-se também dócil e, até o momento, não tem manifestado perturbações da atividade sexual. Nos adultos operados em estado de agitação incontrolada, nenhum efeito benéfico foi conseguido até o momento.

\section{RESUMO}

A atividade do cíngulo anterior pode ser modificada pela ablação ou excitação do hipocampo; partindo dêste princípio, que se baseia em dados experimentais e anatômicos, o autor pensa ser possivel influenciar a evolução de certas enfermidades nervosas e mentais pela ablação do hipocampo.

$\mathrm{O}$ autor realizou 10 intervenções em doentes mentais, sendo 5 ablações bilaterais do hipocampo e 3 unilaterais; nos 2 outros restantes foi feito o acesso simples ao hipocampo sem ablação, o que é o mesmo que fazer o "undercutting" do giro fusiforme.

Nos casos de "undercutting" foram implantados, no hipocampo, eletrodos e agulhas por meio dos quais foram feitas excitações elétrica e química (injeção de acetilcolina com prostigmina e de estricnina) depois de cessado o efeito anestésico. O estímulo elétrico com 5 e 10 ciclos por segundo produziu aumento da amplitude e frequência respiratórias e aceleração do pulso em mais de 10\%. A pressão arterial não foi influenciada. A injeção da acetilcolina com prostigmina produziu apenas elevação da pressão mínima. Os efeitos produzidos pela injeção de estricnina foram semelhantes aos da excitação elétrica, embora menos nítidos.

O pouco tempo de observação e o pequeno número de casos não permitem conclusões sôbre a influência da ablação do hipocampo na evolução dos distúrbios psíquicos e neurológicos. Parece, entretanto, que certos distúrbics de conduta na criança podem ser beneficiados pela ablação bilateral do hipocampo.

\section{SUMMARY}

Anterior cingular activity may be modified after excision or stimulation of hippocampus; taking this as a principle which is based on experimental and anatomical data, the author thinks that the evolution of some 
mental and nervous diseases may be modified by hippocampal ablation. Ten patients were operated upon: 5 were submitted to a bilateral ablation of hippocampus; 3 to unilateral ablation; 2 to undercutting of gyrus fusiformis and approach to hippocampus without excision.

In patients who were submitted to undercutting of fusiform gyrus, electrical and chemical stimulations of hippocampus were performed after cessation of anesthesia. Electrical stimulation with pulsatile current ( 5 and 10 cycles per second) produced increase in respiratory rate and amplitude; pulse rate was increased in more than 10 per cent; no change was verified in blood pressure. Acetylcholine plus prostigmine injection produced only increase of diastolic blood pressure. Effects of strychnine injection were like those verified by electrical excitation but less marked.

Time and number of cases are still insufficient for a definite conclusion about influence of hippocampal ablation on evolution of some neurological and mental disorders. It seems, however, that behavior disorder 3 in children may be beneficially influenced after bilateral excision.

BIBLIOGRAFIA

1. Brodal, A. - 'The hippocampus and the sense of smell. Brain, 70:179-222, 1947. 2. Le Beau, J. -- 'The cingular and pericingular areas in psychosurgery (agitated behavior, obsessive compulsive states, epilepsy). Acta Psychiat. et Neurol. Scandinar, $27: 305-367$, 1952. 3. McCulloch, W. - Cit. por Fulton, J. F.: Physiology of the Nervous System. Oxford University Press, Nova York e Londres, 1949, pág. 464. 4. Smith, W. K. - The functional significance of the rostral cingular cortex as revealed by its responses to electrical excitation. $J$. Neurophysiol., 8:241-255, 1945. 5. Ward Jr., A. A. - The anterior cingular gyrus and personality. Res. Publ. A. Nerv. a. Ment. Dis., 27:438-445, 1948.

$$
\text { Serviço de Neurocirurgia - Hospital Juliano Moreira - Salvador, Bahin. }
$$

